\title{
Liver enzymes and triglycerides predict biomarkers of insulin sensitivity in obese, non - diabetic adult patients
}

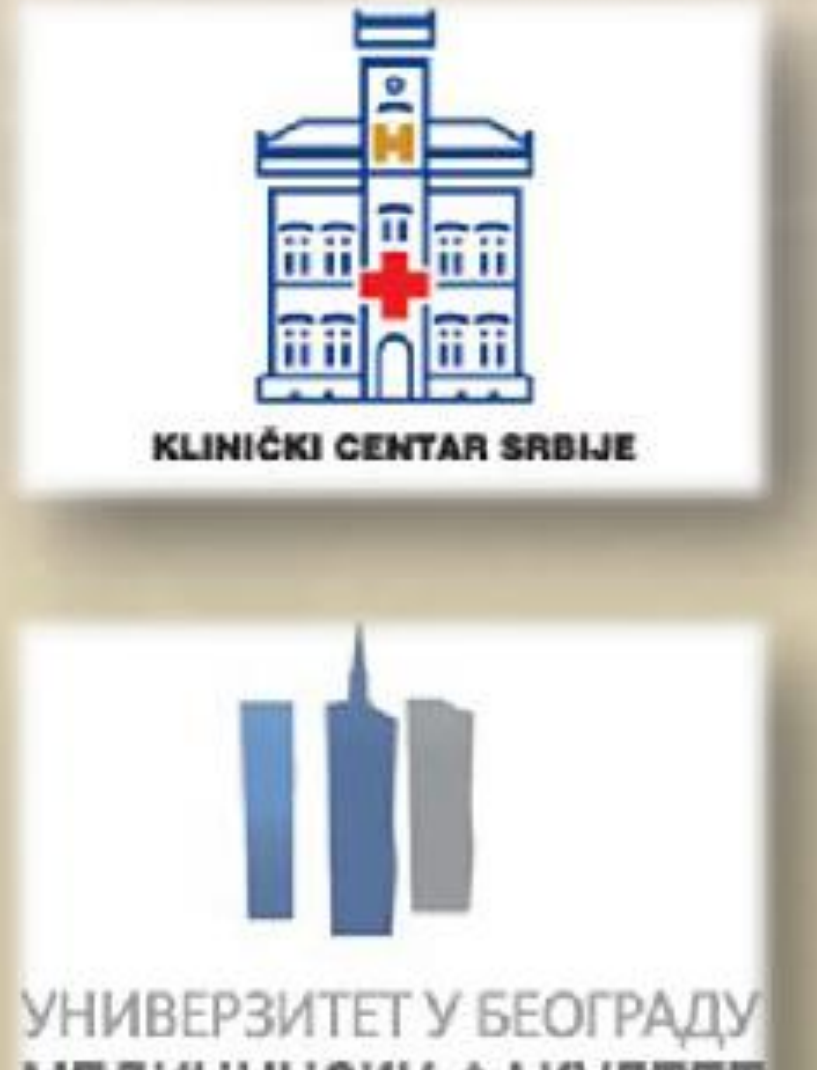

МЕДИЦИНСКИ ФАКУЛТЕТ
A. Gligić ${ }^{1}$ M. Šumarac - Dumanović ${ }^{1,2}$, S. Polovina ${ }^{1}$, D. Stamenković Pejković $^{1}$, G. Cvijović ${ }^{1,2}$, A. Kendereški ${ }^{1,2}$, S. Zorić ${ }^{1}$, D. Jeremić ${ }^{1}$, J. Milin - Lazović ${ }^{1}$, D. Micić ${ }^{1,2}$

1. Clinic for Endocrinology, Diabetes and Metabolic Diseases, Clinical Center of Serbia, Belgrade, Serbia

2. Faculty of Medicine, University of Belgrade, Belgrade, Serbia

\section{Introduction}

Obesity is the key risk factor for the development of insulin resistance, type 2 diabetes, cardiovascular diseases and nonalcoholic fatty liver disease (NAFLD).

NAFLD refers to a spectrum of conditions that ranges from simple hepatic steatosis to more severe disorders, including non-alcoholic steatohepatitis (NASH), fibrosis and finally, cirrhosis. NAFLD is characterized by elevated level of liver enzymes in the circulation. In particular, some prospective studies have shown that ALT and GGT are independent predictors of type 2 diabetes incidence.

\section{Objectives}

- Determination of eventual association between liver enzymes and cardiometabolic risk factors

- Identification of key anthropometric and biochemical parameters that predict insulin sensitivity according to the certain degree of obesity

- Assessing biomarkers in order to target individuals at risk for the introduction of weight management strategies

\section{Methods}

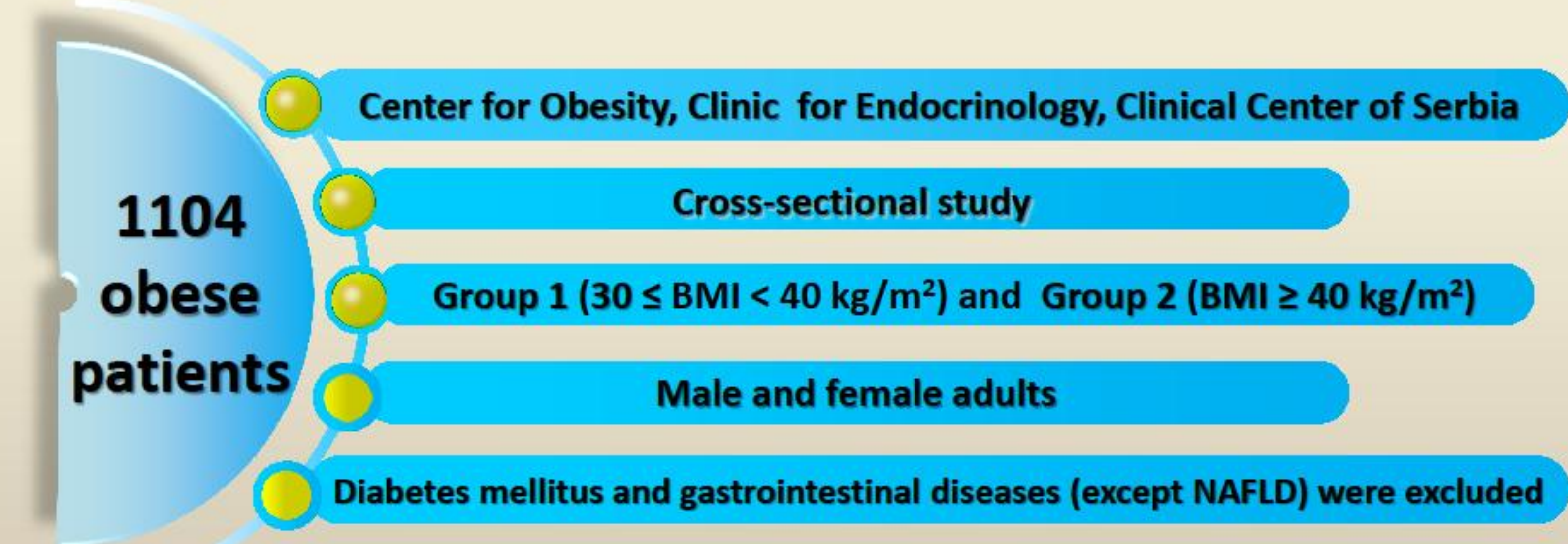

\section{Results}

Table 1. Anthropometric and metabolic characteristics of the study subjects stratified into two groups ( $A$ and $B$ ) according to $B M I$

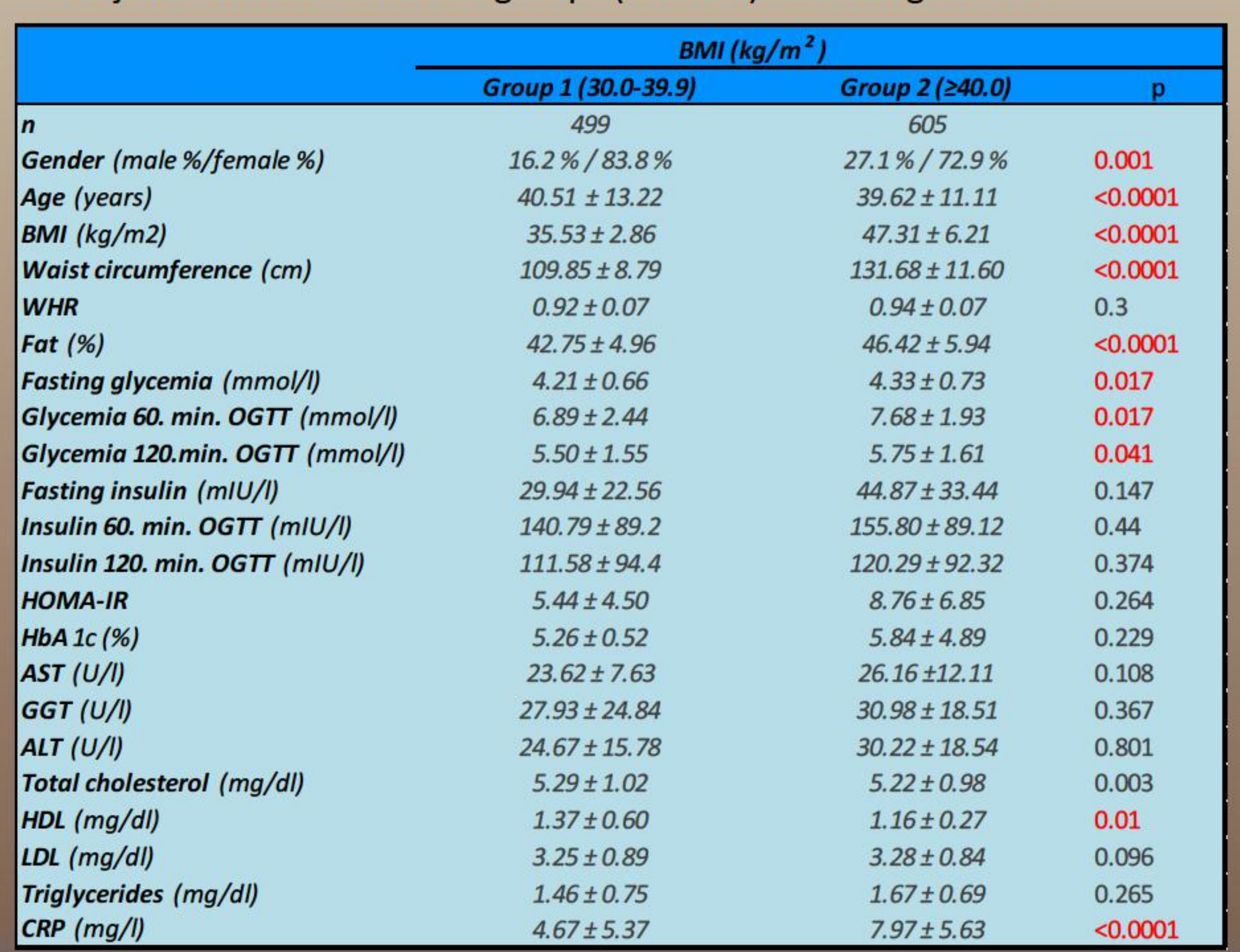

Table 2. Univariate correlations between liver enzymes and anthropometric and metabolic variables (adjusted for age and gender)

\begin{tabular}{|c|c|c|c|c|c|c|}
\hline \multirow[b]{2}{*}{$B M I\left(\mathrm{~kg} / \mathrm{m}^{2}\right)$} & \multicolumn{3}{|c|}{ ALT } & \multicolumn{2}{|l|}{ AST } & $G G T$ \\
\hline & 0.05 & 0.168 & 0.01 & 0.732 & 0.11 & 0.005 \\
\hline waist circumference $(\mathrm{cm})$ & 0.11 & 0.015 & 0.07 & 0.132 & 0.18 & $<0.0001$ \\
\hline WHR & 0.17 & 0.003 & 0.13 & 0.023 & 0.22 & $<0.0001$ \\
\hline Fat (\%) & 0.07 & 0.135 & 0.09 & 0.072 & 0.06 & 0.253 \\
\hline Fasting glycemia $(\mathrm{mmol} / \mathrm{l})$ & 0.08 & 0.049 & 0.04 & 0.358 & 0.08 & 0.042 \\
\hline Glycemia 60. min. OGT (mmol/l) & 0.15 & $<0.0001$ & 0.08 & 0.037 & 0.14 & 0.001 \\
\hline Glycemia 120.min. OGT $(\mathrm{mmol} / \mathrm{l})$ & 0.15 & $<0.0001$ & 0.08 & 0.038 & 0.14 & $<0.0001$ \\
\hline log Fasting insulin (mIU/l) & 0.15 & $<0.0001$ & 0.06 & 0.166 & 0.24 & $<0.0001$ \\
\hline log Insulin 60. min. OGT (mIU/I) & 0.09 & 0.032 & 0.09 & 0.032 & 0.17 & $<0.0001$ \\
\hline log Insulin 120. min. OGT (m/U/l) & 0.16 & $<0.0001$ & 0.15 & $<0.0001$ & 0.18 & $<0.0001$ \\
\hline log HOMA-IR & 0.18 & $<0.0001$ & 0.05 & 0.248 & 0.27 & $<0.0001$ \\
\hline$H b A 1 c(\%)$ & 0.05 & 0.125 & -0.004 & 0.928 & 0.11 & 0.008 \\
\hline $\log C R P(m g / l)$ & -0.02 & 0.577 & 0.001 & 0.974 & 0.11 & 0.011 \\
\hline Total cholesterol ( $\mathrm{mg} / \mathrm{dl})$ & 0.1 & 0.011 & -0.2 & 0.676 & 0.19 & $<0.0001$ \\
\hline HDL ( $\mathrm{mg} / \mathrm{dl})$ & -0.004 & 0.926 & -0.14 & 0.716 & -0.32 & 0.425 \\
\hline LDL $(m g / d l)$ & 0.07 & 0.099 & -0.043 & 0.273 & 0.14 & $<0.0001$ \\
\hline Triglycerides (mq/dl) & 0.14 & 0.001 & 0.063 & 0.108 & 0.18 & $<0.0001$ \\
\hline
\end{tabular}

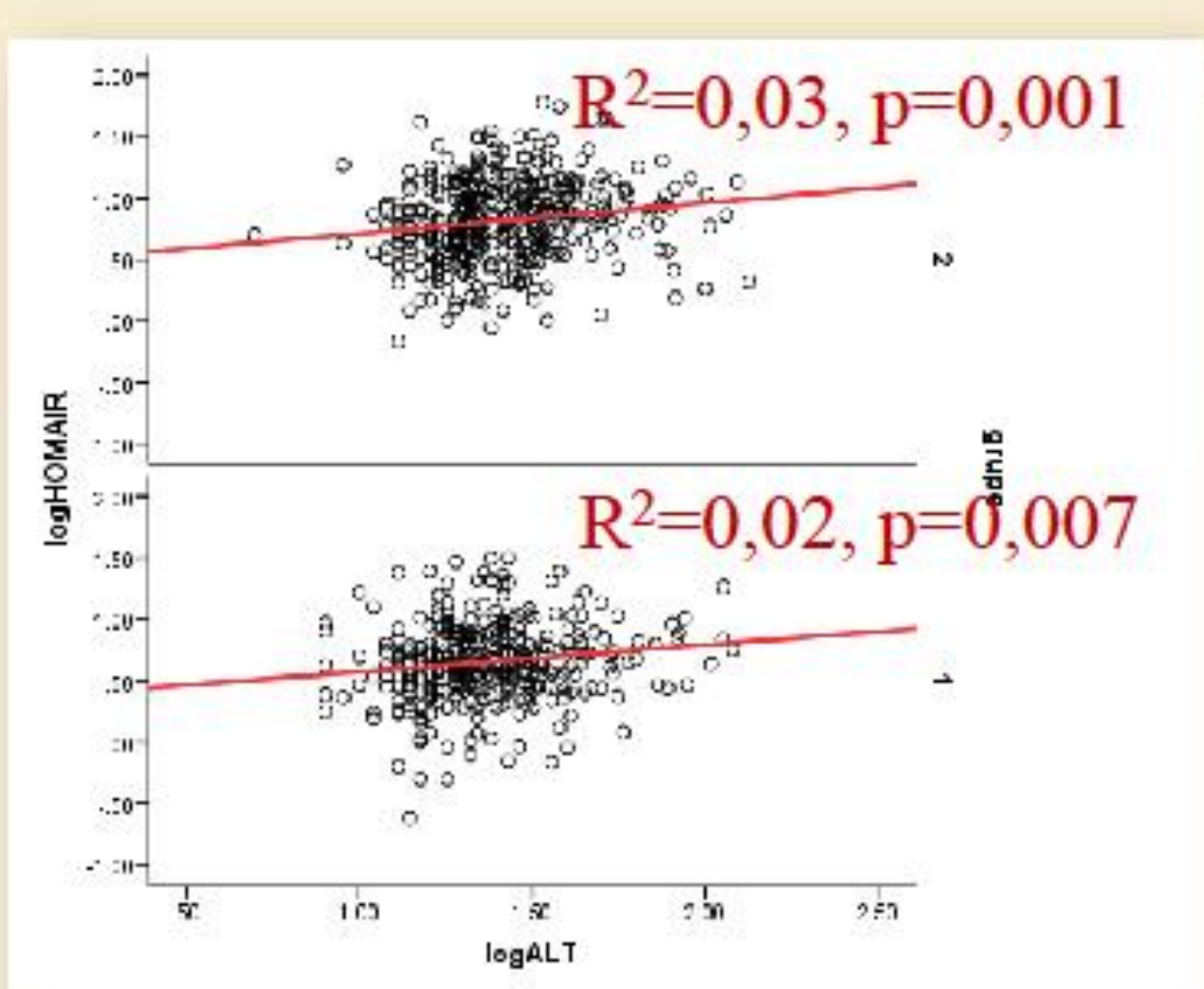

Graph 1. ALT as the predictor of HOMA-IR

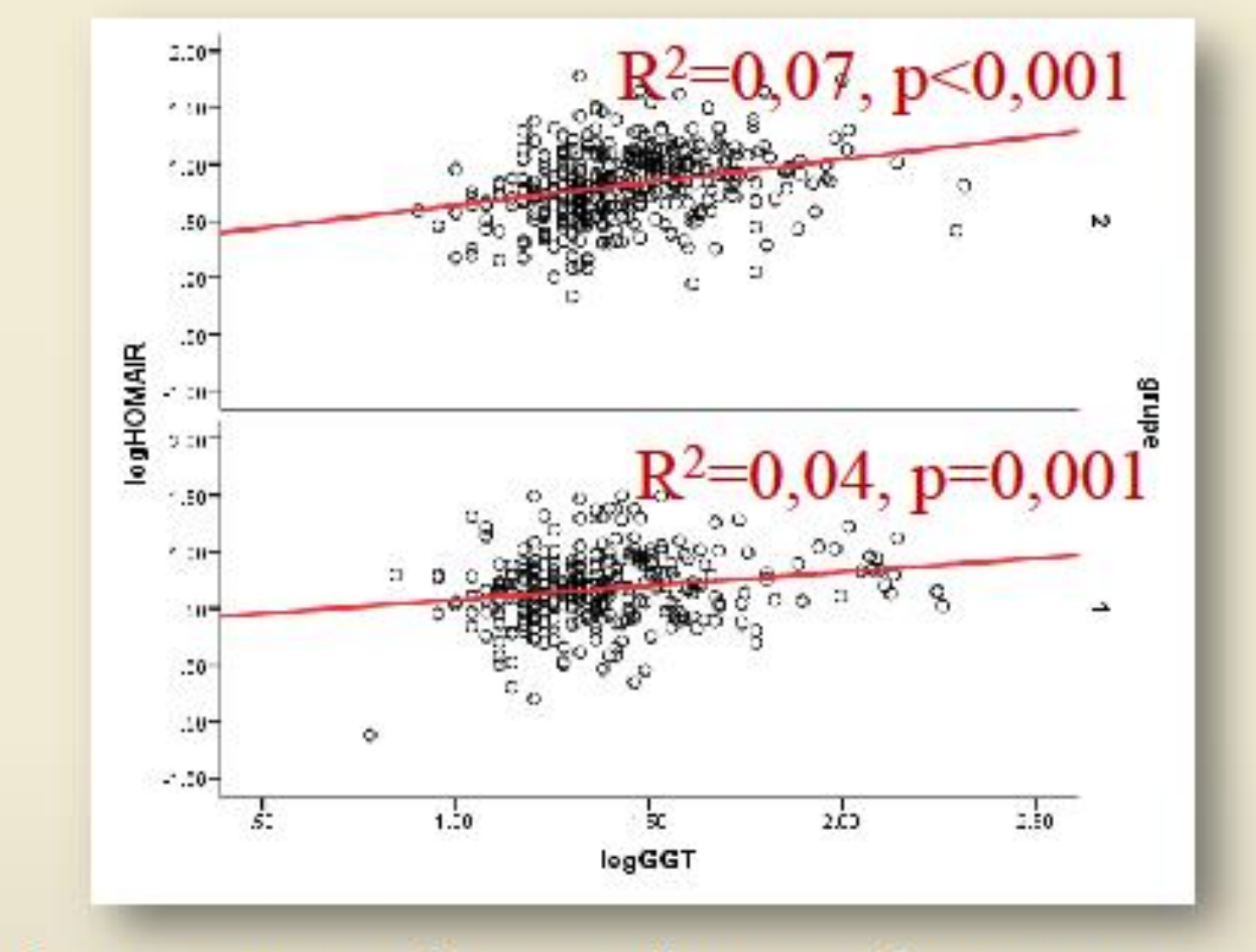

Graph 3. GGT as the predictor of HOMA-IR

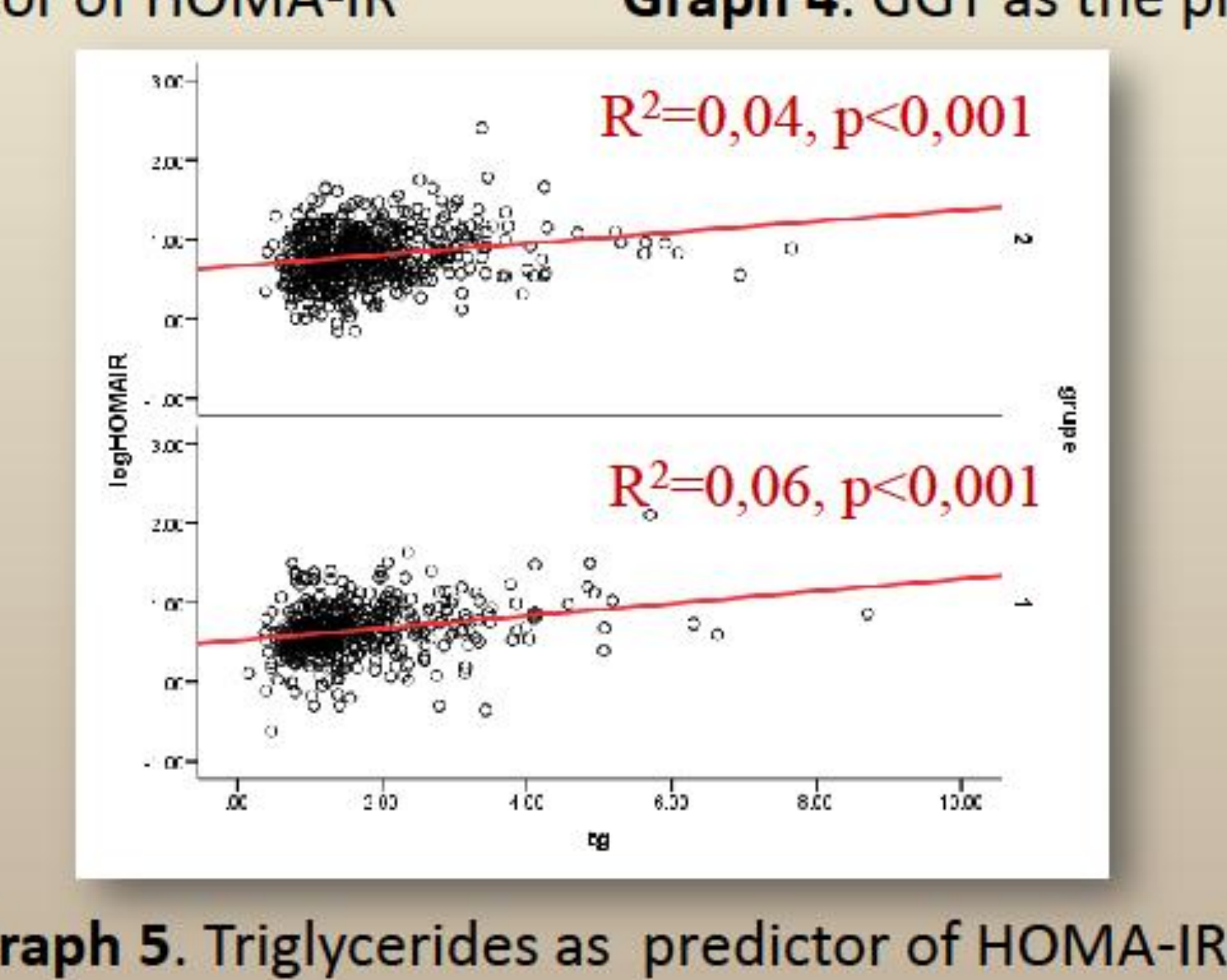

\section{Conclusion}

- A significant correlation was found between liver biomarkers (in particular ALT and GGT) on one hand, and anthropometric parameters of abdominal obesity, HOMA-IR, one- and two- hours post-load plasma glucose and insulin levels and plasma triglycerides, on the other hand

- Parameters of insulin sensitivity and glucoregulation in obese patients could be presumed mainly by levels of liver enzymes and triglycerides regardless of the degree of obesity

\section{References}

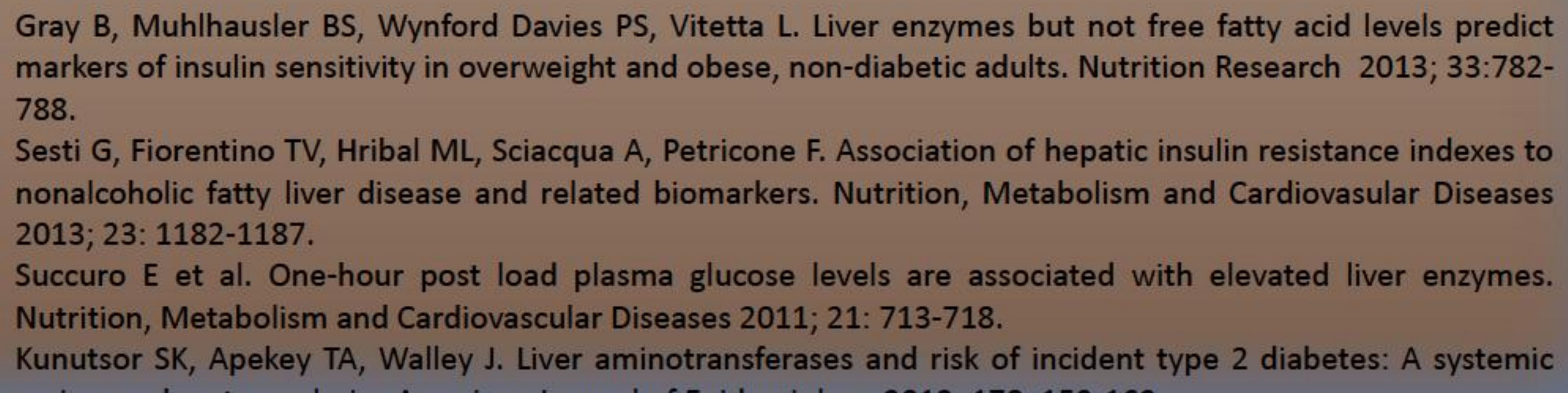
Kunutsor SK, Apekey TA, Walley J. Liver aminotransfer 1 . 73-718. review and meta-analysis. American Journal of Epidemiology 2013; 178: 159-169. 